\title{
Research on the Construction of Digital Portal Website in University Library
}

\author{
Xin $\mathrm{Li}^{1, \mathrm{a}}$ and Bo Guan ${ }^{1, \mathrm{~b}^{*}}$ \\ ${ }^{1}$ Library, Beihua University, Jilin, China \\ ${ }^{2}$ Public Language Institute, Beihua University, Jilin, China \\ alixin198282@163.com, b304230443@qq.com \\ * Corresponding author
}

Keywords: University Library; Portal website; Digital construction

\begin{abstract}
Purpose/significance] Through the construction of high-level digital portal suitable for readers' needs, it can effectively improve the level of information service and the service quality. [Method/process]By analyzing the current situation of library website construction, this paper finds out the advantages and disadvantages in the construction of Library website, the design of library website includes three aspects: the evaluation of website service content, the interface of website style and web service. Web service model of information knowledge navigation will be built and satisfying the new media environment. [Result/conclusion] Through the construction of University Library Digital website, it has become an important window and channel for information navigation and knowledge service of library, providing more effective and timely information service for users.
\end{abstract}

\section{Introduction}

In twenty-first Century, network information technology is more mature and perfect, the network operating system represented by Windows has a strong management and service functions, the Internet technology has been widely used, pay more attention to the digital resources promotion service of university library, traditional library has been unable to meet the reading needs of teachers and students, pushing digital knowledge mobile, delivery and information service has gradually become the main demand of readers. In the Internet era, digital library portal is the library information resources retrieval interface, as well as the base library for users to provide information services at the same time, an intermediary or the reader into the other information resource system. Has become the teachers and students to obtain information and transfer of knowledge and academic research the most important and efficient channels, with the increase in the number of Chinese library portal website, the library website is no longer a simple system of literature and information resources, but rather a rich literature resources based on the comprehensive information service system. Under the network environment, as the number of Internet on university library website is increasing, to carry out research on the construction of library website, website how to aiming at the deficiencies in the construction, raise the level of construction has become a major research issue of common concern.

\section{The present situation of University Library Website Construction}

With the increasing number of electronic resources in university libraries, as well as the behavior of people to obtain information has undergone tremendous changes, people gradually realize the importance of the site. How to present the library website in front of the readers, and the information service quality of the website is closely related. According to the survey, the university library website basically has overview, resource navigation and interactive platform for several large columns, but the columns, the lack of a unified classification of navigation links, set up too many are mainly caused by the lost readers. 


\section{The service content of University Library Website Construction}

Website service content construction mainly the six aspects to design.

General introduction of library lending rules. The module is arranged in the library, readers' guide and other columns, including the library of the history and current situation, the opening time, geographical location and the layout of the library, the library of the relevant policies and regulations, various departments of the library services, the service contacts and email address, library information resources, library the organization and use of library website structure and the distribution of resources, which enables users to have a basic understanding of the traditional library and web site, and then use the traditional library and web information resources.

Electronic resource navigation. That is to provide guidance for the database owned by the library, such as online catalog database, collection database, access to online business database, self built database and so on. Including the introduction of database, the user instructions on how to access the database; the main menu database, understand the connection and disconnection process; introduces the basic retrieval skills, formulate specific methods: display and retrieval of search results, to further refine the strategy and content retrieval.

Reader information inquiry service. Reader information inquiry service mainly includes personal login, password modification, borrowing situation query, library bibliographic navigation and query, new book recommendation, data updates and so on. In this module, it can filter the user's unnecessary information, and actively transmit the user's interested information resources according to the user's customized requirements, so as to realize the personalized information push service. It also has the function of retrieval customization, and can regularly retrieve new collection resources according to the customized retrieval type.

Reference service. The reference service of the traditional library such as telephone counseling service, librarian advisory services, expert guidance services information posted on the Internet, and contact telephone number, service note clearly listed, for users to search the internet. This is not a real online reference service, just use the network to publish information, to provide users with a variety of ways to choose. The library website in this just plays a role of publicity, but for those who prefer to telephone counseling service, librarian advisory services, expert guidance services and other traditional service users, it provides some help for users. The common problems which is based on long-term library reference work in practice and investigation of the user, the user will most likely to ask some questions and answers into a library web site, users encounter problems for fast query. They are usually placed at the site of the site to facilitate user queries and save staff time.

User literacy education. On the one hand, users can retrieve all kinds of information sources, on the other hand, they can learn how to evaluate different information sources, and select the information sources that suit their own needs. The library website is usually in the "literacy services" column in the comprehensive ability of user education, including how to prepare a term paper, how to find all kinds of information resources, literature resources and how to find information according to the subject, how to use the library resources for library information service, and how to evaluate the various types of information resources.

Remote access service. The IP address control method is used to manage the user's authority in the domestic university library websites. Once users are out of the campus network, they have no right to browse some online resources, such as networked databases, electronic journals, e-books and so on, which have caused great inconvenience to the users. In order to solve this problem, the current market is the emergence of a variety of VPN remote access tool, I use the SINFOR Museum and industry and easy to enjoy two off campus remote access system, SINFOR by installing plug-ins in the client browser, the higher level of security, resources and industry VPN access, easy to enjoy through the account password software. No plug-ins, easy access to readers.

\section{Construction and design of style interface of University Library Website}

A good website should have strong technology to support, the technical decision of the website construction should be guided by the user's needs. The website technician should use advanced 
technology to create a simple and beautiful interface conforming to the HTML standard. The design of the website should be compatible with the equipment commonly used by the students. In order to facilitate updates and necessary changes to avoid frustrating link maintenance, all resources should have a home page link. The resources referenced from multiple locations should be directed to a single location so that users will not be confused by conflicting information.

\section{Evaluation of service effect of University Library}

The goal of Web site building is to create a modern interface, website design and website performance is closely related, user positioning is crucial. If a web site can help users to complete their task, they are likely to use it; the students hope to find useful resources in a few seconds, this "quick and easy", "customer satisfaction" is the design of website construction priority elements. Have difficulty in using the web site users need to be able to quickly gain access to help users return to the site and continue to use research tools, this is both for the library website or on the whole school was a success, especially for students in the learning rate.

\section{Summary}

This paper analysis the present situation of the construction of university library website at home, found in the website construction of libraries of advantages and disadvantages from the three aspects of the content of the website service, website style interface and web service evaluation of the planning and design of library website construction, suitable for the new media environment knowledge navigation website information service model. Through the construction of University Library Digital website, it has become an important window and an important channel for library information knowledge and consulting services, providing more effective and timely information services for the vast number of users.

\section{Acknowledgements}

This paper is the relevant research result of the Educational Science Program in Jilin Province " Research on the teaching model reform of Library Literature Retrieval Course under the prosperity of network culture"(project number: GH170053); This paper is the relevant research result of the Teaching and research project of Beihua University (project number: XJQN2017011).

\section{References}

[1] L. Li: Library and Information Service, (2012)No.23,P.33-40. (In Chinese)

[2] P.W. Zhu: Research on Library Science, (2011)No.04,p.35-37.(In Chinese)

[3] A.H. Fan, M. Shao and Y. Zhao: Journal of Academic Libraries, (2006)No.03,p.38-42. (In Chinese)

[4] L. Shi and Z.H. Zhai: Library Journal, (2017)No.05,p.1-9. (In Chinese)

[5] N.X. Zhao and Z.X. Wang: Library and Information Service,Vol:59 (2015)No.11,p.42-47. (In Chinese)

[6] W.J. Li and S.Q. Chen: Library Tribune,Vol:34(2014)No.01,p.74-79. (In Chinese)

[7] K.L. Shen, B. Shao and H. Chen: Library Tribune, Vol:33(2013)No.02,p.107-110. (In Chinese)

[8] J. Du and Y.P. Zhang: Journal of Hebei Institute of Physical Education,Vol:27(2013)No.01,p.79-81. (In Chinese)

[9] L.H. Fu and L.H. Li: Research on Library Science,(2011)No.13,p.17-21. (In Chinese)

[10] Y.N. Xu and L.R. Gan: Journal of Modern Information,Vol:30(2010)No.08:3-7. (In Chinese) 